\title{
Локализованные состояния и фоточувствительность пленок PbSnTe:In в ИК и ТГц областях спектра
}

\author{
А.Э. Климов ${ }^{1,2)}$, А.Н. Акимов ${ }^{1)}$, В.А. Голяшов ${ }^{1,3)}$, Д.В. Ищенко ${ }^{1)}$, Н.С. Пащин ${ }^{1)}$, С.П. Супрун ${ }^{1)}$, \\ А.С. Тарасов ${ }^{1)}$, О.Е. Терещенко ${ }^{1,3)}$, В.Н. Шерстякова ${ }^{1)}$, В.С. Эпов ${ }^{1)}$ \\ ${ }^{1}$ Институт физики полупроводников им. А.В.Ржсанова СО РАН, \\ Новосибирск, 630090, пр. Ак. Лаврентьева, 13 \\ ${ }^{2}$ НГТУ, Новосибирск, 630073, пр-т К. Маркса, 20 \\ ${ }^{3}$ НГУ, Новосибирск, 630090, Пирогова, 2 \\ тел:+7 (383) 330-7883, факс:+7 (383) 333-2766, эл.nочта: klimov@isp.nsc.ru
}

DOI 10.34077/RCSP2019-34

Рассмотрены особенности фоточувствительности структур на основе пленок узкозонного твердого раствора PbSnTe:In, полученных методом МЛЭ на подложках $(111) \mathrm{BaF}_{2}$. Исследованы образцы с содержанием SnTe 24-32 \%, для которых при гелиевых температурах в отсутствие освещения

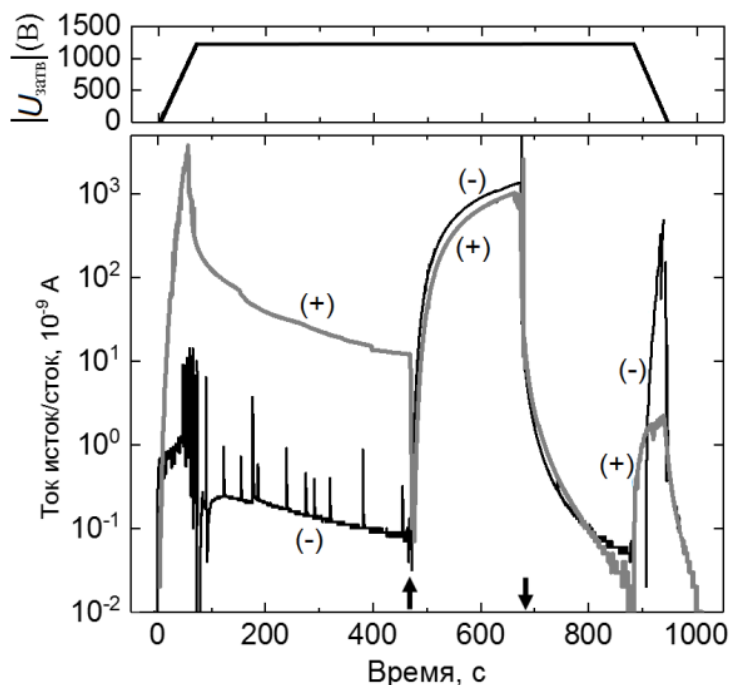

Временные зависимости тока МДПструктуры (внизу) и величины затворного напряжения $\left|U_{\text {затв }}\right|$ (вверху). На рисунке

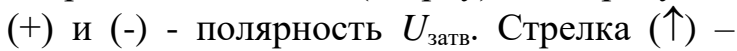
включение, $(\downarrow)$ - выключение освещения в области фундаментального поглощения.

наблюдалось полу-изолирующее состояние [1]. Спектральная чувствительность в ИК области определяется межзонными переходами в условиях захвата одного типа неравновесных носителей заряда на локализованные состояния. Рассмотрены экспериментальные результаты по ИК чувствительности PbSnTe:In МДП-структур (диэлектрик - полипропиленовая пленка толщиной 8 мкм, величина затворного напряжения - до \pm 1250 В), в которых проводимость $n^{+}-i-n^{+}$канала с длиной $i$ области 50 мкм определяется токами, ограниченными пространственным зарядом (ТОПЗ). Из приведенного рисунка видно, что поведение темнового и фототока качественно различно для разных полярностей затворного напряжения $U_{\text {затв- }}$ Так, в момент (个) для $(+)$ наблюдалась отрицательная фотопроводимость с уменьшением тока примерно в 100 раз, тогда как для (-) фототок возрастал монотонно. Для (-) в области t $>880$ с (уменьшение $\left|U_{\text {затв }}\right|$ ) «всплеск» тока для (-) примерно в 100 раз больше по величине и существенно отличается по форме от $(+)$. Это свидетельствует о существенном влиянии на ИК фотопроводимость локализованных состояний, расположенных на поверхности или вблизи нее, что находится в согласии с данными по влиянию химической обработки поверхности на ИК фотопроводимость [2]. Приведены экспериментальные данные по фоточувствительности структур на основе PbSnTe:In в ТГц диапазоне спектра в различных режимах. Полученные результаты анализируются на основе представлений о сложном энергетическом спектре локализованных состояний, которые могут заполняться как при освещении в фундаментальной области поглощения, так и за счет инжекции из контактов в режиме ТОПЗ.

Работа выполнена при частичной поддержке (изготовление образцов) РФФИ, грант №17-02$00575 \mathrm{a}$.

\section{Литература}

[1] Б.А.Волков, Л.И.Рябова, Д.Р.Хохлов // УФН. 2002. Т.172. №8. С.875-906.

[2] A.E.Klimov et al. 4th Asian School-Conference on Physics and Technology of Nanostructured Materials, Vladivostok, Russia, 23-28 September 2018, proceed., p. 82-83. 